\title{
Almost half of patients experience full remission after treatment at a psychiatric clinic
}

Whether the therapist at the district psychiatric centre was a psychologist, psychiatrist or psychiatric nurse seemed to have little bearing on the outcome.

\section{Authors}

\section{Ingrid Olssøn}

Overlege

DPS Elverum-Hamar, Hamar

\section{Alv A. Dahl}

Forskningsrådgiver

Nasjonal kompetansetjeneste for seneffekter etter kreftbehandling, Oslo universitetssykehus, Radiumhospitalet og Universitetet i Oslo

\section{Keywords}

Clinic Mental disorder Symptom Diagnostics Profession

Sykepleien Forskning 2018 13(72553)(e-72553)

DOI: https://doi.org/10.4220/Sykepleienf.2018.72553

\section{ABSTRACT}

Background: The share of consultations at district psychiatric centres is increasing. In a health-economics perspective, it is important to describe the effects of the outpatient treatment provided at such centres. 
Objective: The aim of the study was to map changes in symptom severity and the incidence of mental disorders in patients following treatment at a district psychiatric centre. We also wanted to assess whether the therapist's profession had an impact on these variables.

Method: At Elverum-Hamar district psychiatric centre, we mapped 156 patients before therapy, and 65 patients (42 per cent) participated in a follow-up six years later. Participants reported their own symptom severity and took part in diagnostic interviews before therapy and as part of the follow-up. In separate analyses, treatment outcomes were compared for patients of psychiatric nurses $(n=31)$ and psychologists/psychiatrists $(n=34)$.

Results: In the follow-up, 28 out of 65 patients (43 per cent) showed a clinically significant improvement, and 27 of the 59 patients ( 46 per cent) who were interviewed no longer exhibited a mental disorder. These results were due to a particular improvement in affective disorders. The median number of consultations during the time period was 53 (with a 4-328 spread). There was no significant difference between patients treated by psychiatric nurses and psychologists/psychiatrists. Apart from a higher mean age, we found no significant difference between the patients who showed a clinical improvement and those who did not show any improvement.

Conclusion: Despite numerous consultations at district psychiatric centres, only a moderate share of the patients experienced a significant reduction in symptoms. The profession of the therapists does not seem to impact the effects in the long term.

The white paper concerning the Escalation Plan for Mental Health (1) led to a large increase in personnel and financial resources at the district psychiatric centres. According to the guide for district psychiatric centres (2), the centres are responsible for performing specialised evaluations and providing outpatient, inpatient, ambulant and day-care treatment.

Furthermore, the health services provided at the district psychiatric centres must be safe and effective, and include systems for evaluation and quality assurance. The guide for the centres states that this development and resource allocation should be reflected in the research activity at the centres.

The Norwegian Directorate of Health's report on district psychiatric services from 2015 (3) states the following: 'Adjusted for population growth, outpatient activity increased by 167 per cent during the period 1998-2015. The entire growth stems from the district psychiatric centres. The share of consultations at the centres has thus increased from 53 to 86 per cent of all consultations.' 
Central health authorities have not calculated basic preferred figures for staffing at district psychiatric centres, but they stress the importance of an interdisciplinary group of personnel in which the representation of specialists is strong enough to maintain a well-functioning specialist health service (2). On a national basis, graduates with additional qualifications make up 28 per cent of the clinicians employed at the district psychiatric clinics (3).

\section{Other research in the field}

In a societal and health-economics perspective, it is important to obtain information on the effects of outpatient treatment provided at the district psychiatric centres. It is important to secure systematic knowledge of the changes that patients experience over time, which patients experience change, as well as to map the factors that influence these changes, including the profession of the therapists.

In a literature search in PubMed and CINAHL, we did not find any relevant Norwegian studies from the district psychiatric centres relating to these factors. International research on mental health care concerns the understanding of the nurse's role in general terms (4), mainly described in the context of the primary health service $(5,6)$.

In connection with outpatient specialist health services, literature was found on the nurses' function in defined roles, such as stimulating physical activity (7), and their coordinating role in improving psychiatric patients' access to general practitioners and psychiatrists (8), or to ensure continuity between different treatment levels (9). Some studies compare psychiatric nurses and psychiatrists, but only in a limited clinical context, such as a risk assessment (10, 11). 
We did not find any international research describing patients' perceptions of their degree of improvement or reductions in symptoms where nurses work on a more independent basis in the specialist health service with both evaluations and treatment, as is the case in the district psychiatric centres in Norway. This finding is in line with a report by the Norwegian Directorate of Health (12), which describes the international literature on the subject as follows:

'Such consultation-based services are organised in different ways in different countries, and the type of healthcare personnel involved can vary, including psychiatric nurses, psychologists, psychiatrists or other authorised healthcare personnel. The comparative data on access and use of consultation-based services is limited.’

\section{Objective of the study}

The objective of our naturalistic pilot study was to investigate the extent to which patients experienced full remission after treatment at a general psychiatric clinic. We also wanted to map the factors that affected such remission, including the significance of the therapist's profession.

The research questions in the study were as follows:

Are there significant changes in the symptom severity and the incidence of psychiatric diagnoses in patients treated at district psychiatric centres in Norway when they are followed up six years later on average? If so, what characterises those patients who improve, and is the profession of the therapist significant?

\section{Method}


The study included patients treated at Elverum-Hamar district psychiatric centre, a general psychiatric clinic. The baseline survey covered 156 patients who were evaluated and treated between 1 February 2009 and 15 May 2010. Exclusion criteria in the baseline survey were age below 20 years, clinically perceptible cognitive reduction, psychosis, severe risk of suicide, severe somatic illness or linguistic problems. Patients who abused alcohol or other substances were treated at a different unit in the district psychiatric centres.

In the baseline survey, the therapists asked patients who met the criteria if they were willing to take part. Since the original study had aimed at obtaining a sample in which 50 per cent of participants had a personality disorder, we did not ask all patients. However, it has been documented that the incidence of personality disorders upon referral to the specialist health service is about 50 per cent (13). Additional information about the inclusion process is described in a separate article (14).

In the follow-up survey, we received responses from 65 of the patients (42 per cent). One patient had died and 13 had an unknown address (the correspondence was returned). Thus, 142 patients received a written invitation to participate in the period 22 April 2015-30 March 2016. One reminder was sent, and responses were received from 97 of those invited (68 per cent), of whom 26 (18 per cent) did not want to take part and 4 (3 per cent) did not meet at the agreed time. A total of 67 (47 per cent) therefore participated (Figure 1). 


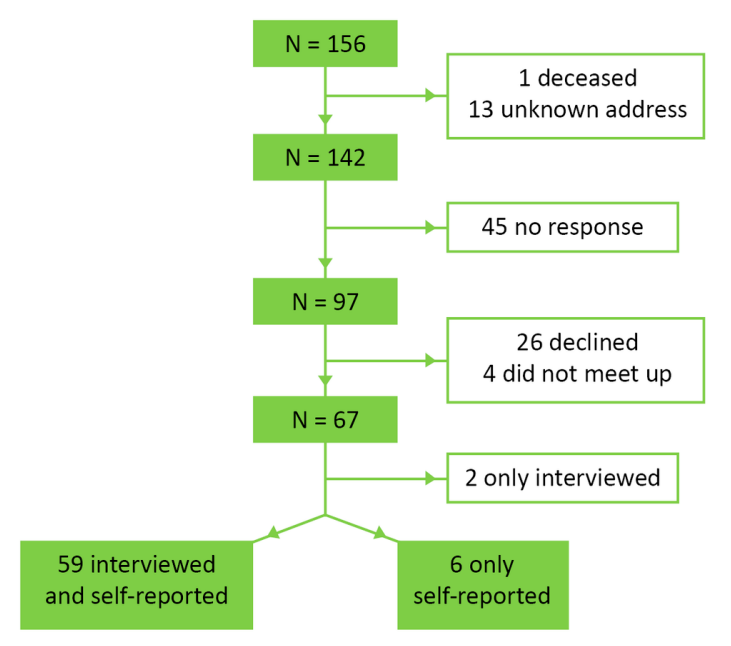

Of the 67 participants, 59 (88 per cent) attended the interview and submitted a satisfactorily completed questionnaire. Six patients only returned a completed questionnaire, and two only attended an interview. Our analyses are based on the 65 patients who responded to the symptom instrument (SCL-90-R, see the section below), and on the 59 patients who took part in a diagnostic interview both as part of the baseline survey and the follow-up.

\section{Demographics}

Demographic data was dichotomised as follows:

marital status in 'married/cohabiting' and 'single', education in ' 12 years of education or less (low)' and 'more than 12 years of education (high)', employment situation in 'paid employment' and 'non-paid employment'.

Full-time and part-time employees and self-employed patients represented the first group, while the unemployed, those on sick leave, benefit recipients and work assessment allowance claimants belonged to the other. Self-reported health related to the question 'How is your health at the moment?', with four response options ('Poor', 'Not so good', 'Good' or 'Very good'), dichotomised as 'Good health' and 'Poor health', with two alternatives in each category (15). 


\section{Checklist for symptom severity}

The Symptom Checklist 90 Revised (SCL-90-R) (16, 17) is an instrument for measuring patients' psychiatric symptom severity in the last week. SCL-90-R consists of 90 questions scored on a five-point scale (0-4) from 'Not at all' to ‘Extremely'.

The Global Severity Index (GSI) measures the general psychopathology in SCL-90-R, and is calculated by adding the scores of the nine sub-scales and dividing this number by the total number of questions. All 65 patients provided complete SCL-90-R responses at both measurement times.

\section{Interviews}

The Mini International Neuropsychiatric Interview (MINI) is a structured interview for axis I diagnoses in the DSM-IV classification. The Norwegian 5.0.0 version from 2007 was used at both measurement times (18).

In the baseline survey, the therapists conducted the MINI interviews, and the distribution of their main diagnoses was 71 per cent for affective disorders, 24 per cent for anxiety disorders and 5 per cent for other disorders. During the follow-up, the first author conducted the MINI interviews.

The SCID-II interview was used to map personality disorders. The interview covers ten specified personality disorders plus the category 'personality disorder not otherwise specified' (19). We used the official Norwegian version of SCID-II, which was last revised in 2004.

The therapists conducted the interviews in the baseline survey, where everyone had already participated in a two-day SCID-II course held by the Norwegian National Advisory Unit on Personality Psychiatry. The therapists found that 41 per cent of the patients had one or more personality disorders. The first author conducted the SCID-II interviews in the follow-up. 
The use of psychopharmaceuticals (antipsychotics, antidepressants, anxiolytics) was only registered at the follow-up interviews.

\section{Therapists}

The profession of the therapists was divided into nurses with further education in psychiatry and a continuing education qualification in therapeutics (cognitive/group analytical therapy) in one group, and psychiatrists, speciality registrars, consultant clinical psychologists and psychologists in the other.

From the electronic journal, we recorded the sum of all treatment contact, i.e. conversations and telephone calls, and further treatment series in addition to the index treatment patients received at Innlandet Hospital's Psychiatric Health Services Division from the start of the baseline survey up to the follow-up survey.

The contact included individual outpatient conversations, group conversations and conversations with therapists as part of inpatient treatment, as well as telephone consultations of at least 15 minutes. Contact with patients by letter or e-mail was not included.

The baseline and follow-up surveys were recommended by the Regional Committee for Medical and Health Research Ethics, South-East Norway (reference number 2014/95). All patients provided written informed consent prior to participation.

\section{Analyses}

We analysed continuous variables using t-tests, and Wilcoxon signed-rank tests were used for skewed distribution, as indicated by an asterisk $\left(^{*}\right)$ in the tables. We used Fisher's exact test to analyse categorical variables. Change over time for continuous variables was analysed using a paired t-test. We measured the effect size of the changes in the GSI score using Cohen's d method (20). 
Clinically significant improvement was set to a reduction of $\geq 0.34$ on the GSI score from the baseline to the follow-up survey since that value corresponded to a standard deviation (SD) of 0.5 of the mean score in the GSI at the baseline survey $(21,22)$. Statistical significance was set to $\mathrm{p}<0.05$, and all tests were twotailed. All analyses were conducted with SPSS version 23 (IBM, Armonk, NY).

\section{Results}

We conducted a drop-out analysis that compared the profession of the therapists, the patients' demographic data and psychopathology in the baseline survey between the 65 patients who participated in the followup survey and the 91 who did not.

The analysis showed only one significant difference those who did not participate were significantly older: 39.4 years $(\mathrm{SD}=11.5)$ compared to 35.4 years $(\mathrm{SD}=$ 11.9). There was no significant difference in the response rate between patients who had seen a specialist nurse and those who had been treated by a doctor/psychologist.

The average time span between the baseline survey and the follow-up survey was 6.1 years $(\mathrm{SD}=0.4)$. The 65 patients who participated had a mean age of 45.5 years $(S D=11.4)$ in the follow-up survey. Sixty per cent were married or cohabiting, 52 per cent had a higher education, and 45 per cent were in paid employment. None of these percentages had changed significantly from the baseline survey (Table 1). 
Table 1. Description of the sample $(n=65)$ in baseline and follow-up surveys

\begin{tabular}{|c|c|c|c|}
\hline Characteristics & Baseline survey & Follow-up survey & p-value \\
\hline Women, $\mathrm{n}(\%)$ & $41(63)$ & & \\
\hline Men, $\mathrm{n}(\%)$ & $24(37)$ & & \\
\hline Age, mean (SD*) & $39.4(11,5)$ & $45.5(11,4)$ & $<0.001$ \\
\hline Married/cohabiting, n (\%) & $32(49)$ & $39(60)$ & 0.29 \\
\hline Higher education, $\mathrm{n}(\%)$ & $31(48)$ & $34(52)$ & 0.73 \\
\hline In paid work, n (\%) & $23(35)$ & $29(45)$ & 0.37 \\
\hline Good health, n (\%) & $19(29)$ & $31(48)$ & 0.05 \\
\hline \multicolumn{4}{|l|}{ Axis I disorder $(n=59)(\%)$} \\
\hline Affective disorder & $42(71)$ & $17(29)$ & $<0.001$ \\
\hline Anxiety disorder & $14(24)$ & $11(18)$ & 0.65 \\
\hline Other disorders & $3(5)$ & $4(7)$ & 1.00 \\
\hline No diagnosis & $0(0)$ & $27(46)$ & $<0.001$ \\
\hline Comorbid axis I + PD** $(n=59)$ & $24(41)$ & $13(22)$ & 0.05 \\
\hline Using psychopharmaceuticals $(n=59)$ & & $16(27)$ & \\
\hline GSI, mean (SD) & $1.4(0,7)$ & $1.1(0.7)$ & 0.00 \\
\hline \multicolumn{4}{|l|}{ Instances of treatment contact } \\
\hline Median (spread) & & $53(4-328)$ & \\
\hline \multicolumn{4}{|l|}{ Profession of therapist, $\mathrm{n}(\%)$} \\
\hline Psychiatric nurse & $31(48)$ & & \\
\hline Psychologist/psychiatrist & $34(52)$ & & \\
\hline Clinical improvement (GSI***), n (\%) & & $28(43)$ & \\
\hline $\begin{array}{l}{ }^{*} \mathrm{SD}=\text { standard deviation } \\
{ }^{* *} \mathrm{PD}=\text { personality disorder } \\
{ }^{* * *} \mathrm{GSI}=\text { The Global Severity Index } \\
\text { Clinical improvement is defined as a reduction of }\end{array}$ & core. & & \\
\hline
\end{tabular}

The percentage who reported good health had increased from 29 per cent to 48 per cent, which was almost significant $(\mathrm{p}=0.05)$. The median treatment contact in this time period was 53, with a spread of 4 to 328 .

Twenty-seven out of 59 patients (46 per cent) did not have a psychiatric diagnosis in the follow-up survey. These cases particularly concerned a reduction in the incidence of affective disorders (71 per cent at baseline and 29 per cent in the follow-up, $\mathrm{p}<0.001)$. The changes were not significant for the other two diagnostic groups. The reduction of patients with comorbid axis I + personality disorders was almost significant $(\mathrm{p}=0.05)$ (Table 1$)$.

The GSI showed a significant improvement in the mean scores in the follow-up compared with the baseline survey, and the effect size was 0.43 measured as Cohen's d. 
The criteria for a clinically significant improvement in the GSI was met by 28 patients (43 per cent). The mean age of these patients was higher than the group of patients who did not show a significant improvement ( $p=0.03$, effect size 0.54 ), but otherwise we found no significant differences between the groups in the baseline survey in terms of sociodemographic data, health or diagnostic occurrence (Table 2).

Table 2. Comparison of patients with and without clinical improvements in the six-year follow-up

\begin{tabular}{|c|c|c|c|}
\hline Characteristics in the baseline survey & $\begin{array}{l}\text { Clinical improvement* } \\
(\mathrm{n}=28)\end{array}$ & $\begin{array}{l}\text { No clinical improvement } \\
(\mathrm{n}=37)\end{array}$ & p-value \\
\hline Women, n (\%) & $14(50)$ & $27(73)$ & 0.06 \\
\hline Men, $\mathrm{n}(\%)$ & $14(50)$ & $10(27)$ & \\
\hline Age, mean (SD**) & $42.9(12,7)$ & $36.8(10,0)$ & 0.03 \\
\hline Good health, $n(\%)$ & $16(57)$ & $16(42)$ & 0.22 \\
\hline Married/cohabiting, n (\%) & $17(61)$ & $22(60)$ & 0.92 \\
\hline Higher education, $\mathrm{n}(\%)$ & $15(54)$ & $19(51)$ & 0.86 \\
\hline In paid work, n (\%) & $10(36)$ & $15(41)$ & 0.80 \\
\hline $\begin{array}{l}\text { Instances of treatment contact, } \\
\text { median (spread) }\end{array}$ & $53(7-184)$ & $56(4-328)$ & 0.92 \\
\hline Further treatment series & $5(19)$ & $14(37)$ & 0.11 \\
\hline Axis I disorder $(n=59)$ & $n=27$ & $n=32$ & \\
\hline Affective disorder & $21(78)$ & $21(66)$ & 0.39 \\
\hline Anxiety disorder & $5(19)$ & $9(28)$ & 0.54 \\
\hline Other disorders & $1(3)$ & $2(6)$ & 1.00 \\
\hline Comorbid axis I + PD*** & $10(37)$ & $14(44)$ & 0.79 \\
\hline Using psychopharmaceuticals, n (\%) & $4(14)$ & $12(32)$ & 0.07 \\
\hline Profession of therapist, $n(\%)$ & & & 0.42 \\
\hline Specialist nurse & $15(56)$ & $16(42)$ & \\
\hline Psychologist/psychiatrist & $13(44)$ & $21(58)$ & \\
\hline \multicolumn{4}{|c|}{$\begin{array}{l}{ }^{*} \text { Clinical improvement is defined as a reduction of } \geq 0.34 \text { in The Global Severity Index score. } \\
{ }^{* *} \mathrm{SD}=\text { standard deviation } \\
{ }^{* * *} \mathrm{PD}=\text { personality disorder }\end{array}$} \\
\hline
\end{tabular}

There was no significant difference in the median number of recorded treatment conversations between those who showed a clinical improvement (53, with a 7-184 spread) and those who did not (56, with a 4-328 spread).

The share that had received two or three treatment series was 19 per cent among those who showed an improvement, and 37 per cent among those who did not show any improvement $(\mathrm{p}=0.11)$. The share using psychopharmaceuticals at the follow-up was 14 per cent among those who showed an improvement, and 32 per cent among those who did not $(p=0.07)$. 
There were no significant differences in improvement between patients treated by specialist nurses and those treated by psychologists/psychiatrists (Table 3).

Table 3. Description of patient sample $(n=65)$ at the follow-up survey based on the profession of the therapist

\begin{tabular}{|c|c|c|c|}
\hline Characteristics in the follow-up survey & $\begin{array}{l}\text { Specialist nurse } \\
\mathrm{n}=\mathbf{3 1}\end{array}$ & $\begin{array}{l}\text { Psychologist/ } \\
\text { psychiatrist } \\
\mathrm{n}=\mathbf{3 4}\end{array}$ & p-value \\
\hline Age, mean (SD*) & $45.3(11.7)$ & $45.7(11.4)$ & 0.89 \\
\hline Gender, n (\%) & & & 0.19 \\
\hline Female & $17(55)$ & $24(70)$ & \\
\hline Male & $14(45)$ & $10(30)$ & \\
\hline Married/cohabiting, n (\%) & $18(58)$ & $21(56)$ & 0.80 \\
\hline Higher education, $\mathrm{n}(\%)$ & $16(52)$ & $18(53)$ & 1.00 \\
\hline In paid work, n (\%) & $13(42)$ & $16(47)$ & 0.80 \\
\hline Good health, n (\%) & $17(55)$ & $14(42)$ & 0.45 \\
\hline $\mathrm{GSI}{ }^{* *}$, mean $(\mathrm{SD})$ & $1.1(0.6)$ & $1.1(0.8)$ & 0.77 \\
\hline $\begin{array}{l}\text { Instances of treatment contact, } \\
\text { median (spread) }\end{array}$ & $53(7-225)$ & $57(4-328)$ & 0.71 \\
\hline Clinical improvement*** (GSI) n (\%) & $15(48)$ & $13(38)$ & 0.41 \\
\hline Diagnoses $(n=59)(\%)$ & $\mathrm{n}=27$ & $\mathrm{n}=32$ & \\
\hline Affective disorder & $8(30)$ & $10(31)$ & 1.00 \\
\hline Anxiety disorder & $5(19)$ & $7(22)$ & 1.00 \\
\hline Other disorders & $1(4)$ & $1(3)$ & 1.00 \\
\hline No diagnosis & $13(47)$ & $14(44)$ & 0.80 \\
\hline Comorbid axis I + PDQ $(n=59)$ & $5(19)$ & $8(25)$ & 0.75 \\
\hline Using psychopharmaceuticals ( $n=59$ ) & $8(30)$ & $8(25)$ & 0.69 \\
\hline \multicolumn{4}{|c|}{$\begin{array}{l}{ }^{*} \mathrm{SD}=\text { standard deviation } \\
{ }^{* *} \mathrm{GSI}=\text { The Global Severity Index } \\
{ }^{* * *} \mathrm{Cl} \text { linical improvement (GSI) is defined as a reduction of } \geq 0.34 \text { in the GSI score. } \\
\mathrm{KPD}=\text { personality disorder }\end{array}$} \\
\hline
\end{tabular}

\section{Discussion}

In the follow-up, 28 patients (43 per cent) showed a clinically significant remission and 27 out of 59 patients (46 per cent) no longer had any mental disorder. This was particularly due to an improvement in affective disorders.

Apart from a higher mean age, we found no significant differences between the patients who showed a clinical improvement and those who did not show any improvement. There were no significant differences in remission between patients treated by psychiatric nurses and those treated by psychologists/psychiatrists.

\section{Therapeutic efforts and treatment contact}


Viewed in the context of the median treatment contact of 53, it is reasonable to describe the share of 43 per cent with a full remission as modest. Finding researchbased comparison data for such a heterogeneous patient group has, however, proven to be difficult. We consider 53 instances of treatment contact to be high. By comparison, cognitive therapies of 10-15 hours and dynamic short-term psychotherapy of 12-20 hours are often recommended for axis I disorders, such as anxiety and depression.

\section{三 «We consider 53 instances of treatment contact to be high.»}

However, the clinical reality in the specialist health service often entails patients with complex disorders, and it has therefore been necessary in countries such as Denmark to extend the dimensions of care pathways for psychiatric disorders, which originally indicated 15 and 18 hours respectively for these disorders.

In the Norwegian Directorate of Health's consultation paper (23) on care pathways for treatment in mental health services, no specific number of hours has been given. Although the symptom level was not checked at the start of the treatment, it is interesting to note that the incidence of treatment contact overlaps between the group that showed an improvement and the one that did not.

This finding can be interpreted in several ways that can be of major importance to the treatment at district psychiatric centres, if we dare to generalise. One interpretation is that much of the treatment contact is of a general nature, and does not entail evaluations being done of whether the patient is actually improving along the way. Another point of view is that evaluations are done, but that the therapists choose to continue with patients who, realistically, have little potential for change or who are not particularly motivated. 
A third interpretation is that finalising treatment with a patient and taking on new patients requires a lot of work and documentation. This requirement may lead to therapists retaining patients out of convenience, whereby the contact increases without any wellfounded professional basis.

\section{Associated factors for improvement}

Symptom improvement is not significantly associated with being employed or having good self-reported health, but this finding may correlate to possible type II errors. Of the 65 patients who participated, the share in paid work and with self-reported good health increased by 10 and 19 percentage points respectively (Table 1).

Our findings imply that both the socio-economic and personal gain over time is moderate, while other factors that were not mapped in the study may also play a role. For example, a reduced incidence of affective disorders at the follow-up may be due to spontaneous remission (24). Another example is the use of antidepressants. Unfortunately, we do not have data on how many patients were taking antidepressants at the time of referral or were prescribed them during the course of the baseline survey.

Our therapists are well acquainted with the national guidelines for treating anxiety disorders and affective disorders. However, we have not specifically mapped the extent to which the guidelines were followed. The Norwegian Directorate of Health assumes that the treatment given in the psychiatric specialist health service complies with these guidelines.

Since the treatment outcome in the study is moderate in relation to the extent of treatment given, we believe that treatment guideline compliance would be a useful area of research in new studies of treatment outcomes at district psychiatric centres.

\section{Profession}


The therapists at district psychiatric centres have different occupations and professional experience, and their theoretical fields of interest and level of further education also differ. By virtue of their expertise, psychiatric nurses with a continuing education qualification in therapeutics have attained a high level of independence as therapists.

An interesting question is whether specialist nurses achieve treatment outcomes that do not differ materially from those achieved by psychiatrists and psychologists. A profession-based analysis showed no significant differences in the treatment outcome. Nor did 'sicker' patients with higher GSI scores in the baseline survey show a skewed distribution between the two groups of professions. The finding supports the claim that specialist nurses have an equal value as therapists in interdisciplinary collaborations vis-à-vis patients referred to general psychiatric clinics at the district psychiatric centres.

\section{三 «A profession-based analysis showed no significant differences in the treatment outcome.»}

Patients whose therapist was a specialist nurse in the baseline survey may have been treated by a doctor or psychologist in subsequent treatment series, and vice versa. Due to the throughput of therapists, professions or therapists may also have changed during the baseline survey itself. We do not have data on such changes, but our impression is that they did not occur often enough to affect the result. 
Several professions with three-year undergraduate programmes today offer the opportunity to study for a master's degree in mental health work. The Norwegian Nurses Organisation's professional interest group for nurses within mental health and substance abuse is working to introduce a master's degree based on a purely nursing specialisation (25), while others believe that nurses need a master's degree in psychiatric treatment (26).

We believe that our findings may be of significance to the ongoing discussion concerning professions and staffing policy at district psychiatric centres. There is no doubt a difference between the professions in terms of pay, however this study found that the profession of the therapist had no impact on the patients' degree of improvement.

\section{Earlier studies}

We did not find any research on specialist nurses' results with conversational therapy at a specialist level, but the nurse's role and function in municipal health and substance abuse work is well documented in a report (27). The report shows that the majority of nurses working in mental health and substance abuse have further education and more than five years of clinical experience. It also shows that those who work in a clinical setting have the highest levels of education, but does not mention treatment outcomes.

The Norwegian Directorate of Health's report (12) states that there is little international research that satisfactorily compares the outcomes achieved between the various professions employed in psychiatric clinics in the specialist health service.

\section{Strengths and limitations of the study}


In principle, we believe that our patient dataset on affective disorders (mostly depression), anxiety disorders and comorbid personality disorders is fairly representative of what is generally treated at general psychiatric clinics at district psychiatric centres in Norway with a similar organisation. The drop-out analysis showed minimal differences in the baseline survey between those who participated in the followup survey and those who did not, which reinforces the representativeness of the material.

In the follow-up, 17 per cent $(n=26)$ of invited patients declined to participate, and this may be due to the experiences with the district psychiatric centres, the treatment outcome or a need to put this particular period of their life behind them. This may also be the case for the 45 patients (29 per cent) who did not respond.

It is difficult to know whether the 46 per cent who did not take part in the follow-up would have had a positive or negative effect on the share who experienced full remission. There was no significant difference in the response rate between patients who saw a specialist nurse and those who were treated by a doctor/psychologist.

Based on our experience, almost half of former outpatients at district psychiatric centres will participate in a follow-up survey six years after starting treatment. This finding may be of importance when planning new follow-up studies at general psychiatric clinics at district psychiatric centres.

We believe that the participation rate may increase if patients are referred by their previous therapists rather than a senior consultant that the patient is not familiar with, or if the patients are given an incentive to participate. The fact that the follow-up was conducted after six years is a strength in that it enables patients to take a retrospective view of the treatment and weigh up its importance in relation to other life events. 
The drop-out rate in the study and lack of information on the extent to which the therapies were terminated by agreement represent a weakness in our findings, with a probable selection bias towards patients who were either satisfied with the treatment and/or were satisfied with their current life situation. The drop-out rate also means that the groups we examined were small and had an increased risk of statistical type II errors. This means that several differences could have been significant if our group had been larger, which in itself is a weakness of the study.

A third weakness is the lack of consideration that our design gave to possible intermediate variables in the six-year follow-up period. Intermediate variables can include negative life events during the follow-up period, such as the death of a close relative, the breakdown of a relationship or unemployment. Over a six-year period, we must also consider that spontaneous remission may occur. Despite these weaknesses, we cannot preclude treatment as an explanatory factor for the registered improvement.

The final weakness relates to the diagnostics being carried out by several therapists in the baseline survey, but only the first author in the follow-up, despite the same diagnostic tools being used in both surveys. We therefore decided to change the self-reported symptom severity (GSI) as our primary outcome measurement.

\section{Implications of the study}

A few years ago, one of Norway's leading psychiatrists, Trond F. Aarre (28), wrote that psychiatry should not require more resources, but should rather assess the way in which the employees work. Our findings seem to support Aarre's conclusion. It is positive that resources are added, but it is worrying that, despite the requirement in the regulations, little research is done on the impact of the treatment at the district psychiatric centres on patients' function and symptom level. 
Central health authorities and regional health authorities should therefore jointly map possible obstacles and initiate measures to stimulate treatment research at the district psychiatric centres. The production requirement at the centres is high, and planning and conducting research that increases the workload of the therapists is a challenge.

\section{Conclusion}

Central health authorities require mental health care to be beneficial and cost effective. Our study shows that despite a high instance of treatment contact at district psychiatric centres, only a moderate share of patients experience full remission. The profession of the therapist appears to have no bearing on this finding.

Our results indicate that there is a need to review patient selection and working methods at the general psychiatric clinics at district psychiatric centres. There is also a need to investigate whether patient selection and working methods are in line with current national guidelines for the most common diagnoses.

Thanks go to specialist nurse Hildur Rosenlund Engen, who assisted with the data collection and proofread the manuscript.

\section{References}

1. St.prp. nr. 63 (1997-98). Om opptrappingsplan for psykisk helse 1999-2006. Oslo; Sosial- og helsedepartementet 1998. Available at: https://www.re gjeringen.no/no/dokumenter/stprp-nr-63-1997-98- /id2 01915/ (nedlastet 20.11.2017).

2. Sosial- og helsedirektoratet. Distriktspsykiatriske sentre - med blikket vendt mot kommunene og spesialiserte sykehusfunksjoner i ryggen. Oslo; 2006. Veileder IS-1388. Available at: https://helsedirektorate t.no/retningslinjer/distriktspsykiatriske-sentre-med-bli kket-vendt-mot-kommunene-og-spesialiserte-sykehusf unksjoner-i-ryggen (nedlastet 05.09.2018). 
3. Helsedirektoratet. Distriktspsykiatriske tjenester 2015. Driftsindikatorer for distriktspsykiatriske sentre. Oslo; 2016. Rapport IS- 2579. Available at: https://hels edirektoratet.no/publikasjoner/distriktspsykiatriske-tje nester-driftsindikatorer-for-distriktspsykiatriske-sentre (nedlastet 05.09.2018).

4. Hurley J, Lakeman R. Becoming a psychiatric/mental health nurse in the UK: A qualitative study exploring processes of identity formation, Issues in Mental Health Nursing. 2011;32(12):745-51.

5. Barlow K. Perceptions of the role of the community psychiatric nurse. Nurs Times. 2006;102(9):34-8.

6. Chamberlain-Salaun J, Mills J, Park T. Mental health nurses employed in Australian general practice: Dimensions of time and space. International Journal of Mental Health Nursing. 2011;20(2):112-8.

7. Happell B, Platania-Phung C, David Scott D. Proposed nurse-led initiatives in improving physical health of people with serious mental illness: a survey of nurses in mental health. Journal of Clinical Nursing. 2014; 23(7-8):1018-29.

8. Happell B, Palmer C, Tennent R. Mental. Health nurse incentive program: Contributing to positive client outcomes. Intern J of Mental Health Nursing. 2010;19(5):331-9.

9. Rose LE, Gerson L, Carbo C. Transitional care for seriously mentally ill persons: a pilot study. Arch Psychiatr Nurs. 2007;21(6):297-308.

10. Weston SN. Comparison of the assessment by doctors and nurses of deliberate self-harm. Psychiatric Bulletin. 2003;27(2):57-60. 
11. Murphy E, Kapur N, Webb R, Cooper J. Risk assessment following self-harm: comparison of mental health nurses and psychiatrists. J Adv Nurs. 2011;67(1):127-39.

12. Helsedirektoratet. Internasjonalt perspektiv på psykisk helse og helsetjenester til mennesker med psykiske lidelser. Oslo; 2015. Rapport IS-2314.

Available at: https://helsedirektoratet.no/publikasjoner/ internasjonalt-perspektiv-pa-psykisk-helse-og-helsetje nester-til-mennesker-med-psykiske-lidelser (downloaded 05.09.2018).

13. Alnaes R, Torgersen S. DSM-III symptom disorders (Axis I) and personality disorders (Axis II) in an outpatient population. Acta Psychiatr Scand. 1988;78(3):348-355.

14. Olssøn I, Sørebø Ø, Dahl AA. A cross-sectional testing of the Iowa Personality Disorder Screen in a psychiatric outpatient setting. BMC Psychiatry. 2011; 11:105. Available at: https://bmcpsychiatry.biomedcent ral.com/articles/10.1186/1471-244X-11-105 (downloaded 20.11.2017).

15. Norges teknisk-naturvitenskapelige universitet. Helseundersøkelsen i Nord-Trøndelag. Available at: htt p://www.ntnu.no/hunt/skjema (downloaded 20.11.2017).

16. Derogatis LR. SCL-90-R: administration, scoring and procedures manual. Minneapolis, MN: National Computer Systems; 1994.

17. Pedersen G, Karterud S. Is SCL-90R helpful for the clinician in assessing DSM-IV symptom disorders? Acta Psychiatr Scand. 2004;110(3):215-24.

18. Sheehan DV, Lecrubier Y, Janvas J, et al. Mini International Psychiatric Interview (MINI) version 5.0.0. Tampa, FL: University of South Florida, Institute for Research in Psychiatry og Paris: INSERM-Hôpital de la Salpetière; 2006. 
19. First MB, Gibbon M, Spitzer R.L, Williams JBW, Benjamin LS. Structured clinical interview for the DSM-IV Axis II Personality Disorders (SCID-II). Washington, DC: American Psychiatric Press; 1997.

20. Cohen J. Statistical power analysis for the behavioral sciences. New York: Routledge; 1998.

21. Jacobson NS, Truax P. Clinical significance: a statistical approach to defining meaningful change in psychotherapy research. J Consult Clin Psychol. 1991;59(1):12-9.

22. Sloan JA, Vargas-Chanes D, Kamath CC, Sargent DJ, Novotny P, Atherton P, et al. Detecting worms, ducks, and elephants: A simple approach for defining clinically relevant effects in quality-of-life measures. J Cancer Integr Med. 2003;1:41-7.

23. Helsedirektoratet. Pakkeforløp for behandling i psykisk helsevern, voksne. Høringsutkast. Oslo; 2018. Available at: https://helsedirektoratet.no/horinger/beha ndling-i-psykisk-helsevern-voksne-pakkeforlop (downloaded 12.02.2018).

24. Fuller-Thomson E, Battiston M, Gadalla TM, Brennenstuhl S. Bouncing back: remission from depression in a 12-year panel study of a representative Canadian community sample. Soc Psychiatry Psychiatr Epidemiol. 2014;49(6):903-10.

25. Lyngved K. Bedre masterutdanning. Psykisk helse og rus. 2016;03.

26. Schei Å. Vi trenger en master i psykiatrisk behandling. Sykepleien. 2014;01. Available at: https:// sykepleien.no/forskning/2014/01/vi-trenger-en-masteri-psykiatrisk-behandling (downloaded 29.08.2018). 
27. Senter for psykisk helse og rus. Sykepleie i

kommunalt psykisk helse- og rusarbeid.

Forskningsrapport nr. 16 /2015. Available at: https://he

lsedirektoratet.no/Documents/Psykisk\%20helse/Rappo

rt_IS24_8_2017.pdf (downloaded 05.09.2018).

28. Aarre TF. Manifest for psykisk helsevern. Oslo:

Universitetsforlaget; 2010. 